\title{
Organic Compounds and Inorganic Metals Removal from Wastewater Using Klebsiella pneumoniae and Acinetobacter Iwoffii
}

\author{
EL-Gamal, M.S. ${ }^{1}$, El-Shahawy, M.R. ${ }^{2}$, Fouda, A. ${ }^{1}$, Bekhit, H.A. ${ }^{3}$
}

Received: 07/08/2018

Accepted: 26/09/2018

E.mail:hashim.arafa@yahoo.com

\section{KEYWORDS}

Abu Rawash

Wastewater Plant,

Klebsiella pneumonia,

Acinetobacter lwoffii,

Heavy Metal, Mineral

Silica Oil (MSO),

Tryptic Soy Agar

(TSA).

\section{ABSTRACT}

Wastewater contains high levels of organic material, numerous pathogenic microorganisms, as well as nutrients and toxic compounds. Wastewater samples were collected from influent of different wastewater treatment plant. Klebsiella pneumoniae and Acinetobacter lwoffii were isolated from the samples and these isolates were screened for the reduction of wastewater components which estimated by COD (Chemical Oxygen Demand), BOD (Biological Oxygen Demand), and TSS (Total Suspended Solids) values. Wastes reduction by the isolated bacteria using different $\mathrm{pH}$ values, incubation temperatures, inoculum volume, static and dynamic condition with different incubation periods and bioremediation the variable concentrations of metals in singles and mixtures states were studied. Our investigate show the optimum conditions at $\mathrm{pH} 7,35^{\circ} \mathrm{C}$, dynamic condition, $0.5 \%$ standard inoculum volume for K.pneumoniae and $2 \%$ for A.lwoffii, 48 hours' incubation period, and metals concentrations $5 \mathrm{ppm}$.

1. Botany \& Microbiology Department, Faculty of Science, Al-Azhar University, Cairo, Egypt.

2. Radiation Microbiology Dept, National Center for Radiation Research and Technology, Egyptian Atomic Energy Authority, Cairo, Egypt.

3. Reference Lab for Wastewater, Cairo, Egypt. 


\section{INTRODUCTION}

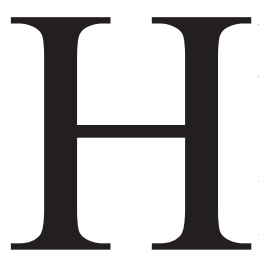

uman sewage and waste from manufacturing industries was the main source for wastewater. The total volume of wastewater from industry is about 7 times that of domestic sewage. If untreated, and discharged directly to the environment, the receiving waters would become polluted and water-borne diseases would be widely distributed (Davies, 2005). Untreated wastewater generally contains high levels of organic material, pathogenic microorganisms, as well as nutrients and toxic compounds. It thus entails environment and health hazards, therefore, it must immediately transported away from its generation sources and treated appropriately before final disposal. The release of high amounts of heavy metals into water bodies creates serious health and environmental problems and may lead to an upsurge in wastewater treatment cost, to prevent the negative effects of heavy metals toxicity in wastewater, there is need for adequate treatment of effluents before discharge to receiving water bodies (Oghenerobor et al., 2014; Fouda et al., 2016). Egypt faces a rapidly increasing deterioration of its surface and groundwater due to increasing discharges of heavily polluted domestic and industrial effluents into its waterways. There are estimated to be some 24,000 industrial enterprises in Egypt, about 700 of which are major industrial facilities. Egyptian industry uses 638 Million $\mathrm{m}^{3} / \mathrm{yr}$. of water, of which 549 Million $\mathrm{m}^{3} / \mathrm{yr}$. is discharged to the drainage system. Industrial activities in the Greater Cairo and Alexandria regions use $40 \%$ of the total. The River Nile supplies $65 \%$ of the industrial water needs and receives more than 57\% of its effluents (Mohamed et al., 2013). The domestic pollution affects water quality heavily depends on the way of disposal of pollutants. Approximately 65 percent of Egypt's population is connected to drinking water supply and only 24 percent to sewage services, although the latter percentage is expected to grow rapidly, due to works under construction. The population not connected to sewage systems relies on individual means of excreta and wastewater disposal such as latrines and septic tanks. The domestic wastewater spread into soil and groundwater by discharging and collecting wastewater in permeable septic tanks. The domestic wastewater is considered as the main source of pollution of groundwater. It contains many toxic and injurious chemical constituents that have serious effect on public health problems (Easa and Abou-Rayan, 2010). The ultimate goal of wastewater management is the protection of the environment in a manner commensurate with public health.(ESCWA 2010). Different wastewater treatment methods or systems with minimum electric requirements and low maintenance costs were needed to overcome problems or hazardous of conventional methods currently used. (Mara et al., 1992; Brix, 1994; Vymazal, 2002; Bécares, 2006; Puigagut et al., 2007). In the early years of the twentieth century the method of biological treatment was devised, and now forms the basis of wastewater treatment worldwide. In the biological treatment the naturally occurring bacteria, together with some protozoa and other microbes, are collectively referred to as activated sludge. The concept of treatment is very simple. The bacteria remove small organic carbon molecules by 'eating' them. As a result, the bacteria grow, and the wastewater is cleansed. The treated wastewater or effluent can then be discharged to receiving waters normally a river or the sea (Lin, 2007).

Therefore, this study aimed to:

1- Isolation the total bacterial consortia from different wastewater samples.

2- Screening and selection of the most potent isolates which play important role in wastes reduction in wastewater.

3- Identification of the most potent isolates and optimized the bacterial treatment conditions $(\mathrm{pH}$, temperatures, inoculum size and incubation condition (static and shaking) at different incuba- 
tion period) for enhanced wastewater treatment.

4- Study the effect of different concentrations of metals on isolates growth count, metals bioremediation and wastes reduction.

\section{MATERIALS AND METHODS}

\section{Samples collection}

Wastewater samples were collected from three different wastewater plant represented by Abu Rawash Wastewater plant (primary treatment), Egypt Alexandria desert road, giza, Egypt, El tanqia El sharqia Wastewater plant (Secondary treatment), the east Alexandria (beside Beirut university, El-Ramel Station), Egypt and Shobra El-khema Wastewater plant, ring road, Qalubia, Egypt.

The Wastewater samples were collected in sterile closed bottles; and dipped in the subsurface and transferred within 6 hours for Lab. and culturing immediately. The remaining samples from each one used for chemical analysis and total bacterial count.

\section{Isolation and purification of total bacteria isolates}

The collected wastewater samples were serially diluted using phosphate buffer. One $\mathrm{ml}$ of each dilution was inoculated on Tryptic Soy Agar (TSA) (containing g/L: Pancreatic digest casein, 15; Pancreatic digest soybean, 5; Sodium chloride, 5; Agar, 15; dis. $\left.\mathrm{H}_{2} \mathrm{O}, 1 \mathrm{~L}\right)$ for $24 \mathrm{~h}$ at $35 \pm 2^{\circ} \mathrm{C}$. The isolates were purified by re-streaking separately on TSA. Morphological characterization of purified isolates were be done.

\section{Screening and selection of the most potent bacteria}

The purified bacterial isolates were growing on Mineral Silica Oil (MSO) containing diesel oil as only carbon source (EL Shahawy, 2007). Five $\mathrm{ml}$ of each separately bacterial isolates (adjusted at O.D. $)$ were inoculated in $500 \mathrm{ml}$ wastewater and incubated for 7 days at $35^{\circ} \mathrm{C}$. Bacterial isolates have the ability to grow on diesel oil as only carbon source selected for growing on $500 \mathrm{ml}$ wastewater to select most potent isolates according to COD, BOD, TS, TSS and $\mathrm{pH}$ a triplicate for each organism on each sample. Control was raw wastewater sample and sterilized raw wastewater without inoculation.

\section{Molecular identification of most potent bacterial isolates}

The most potent bacterial isolates were identified by 16S rRNA gene as the following:

- DNA extraction using protocol of GeneJet genomic DNA purification Kit (Thermo K0721).

The bacterial cell (up to $2 \times 10^{9}$ ) was harvested in a 1.5 or $2 \mathrm{ml}$ micro centrifuge tube by centrifugation for $10 \mathrm{~min}$ at $5000 \mathrm{x} \mathrm{g}$. the cell was completely digested and lysed. The prepared lysate transferred to a GeneJET ${ }^{\mathrm{TM}}$ Genomic DNA Purification Column inserted in a collection tube. The purified DNA was used immediately in PCR.

- PCR using Maxima Hot Start PCR Master Mix (Thermo K1051).

Gently vortex and briefly centrifugation Maxima ${ }^{\circledR}$ Hot Start PCR Master Mix (2X) after thawing. The following components were added for each $50 \mu$ reaction at room temperature: Maxima ${ }^{\circledR}$ Hot Start PCR Master Mix (2X) $25 \mu \mathrm{l}, 16 \mathrm{SrRNA}$ Forward primer 1ul (20uM), 16SrRNA Reverse primer (of each 8 primer) 1ul(20uM), Template DNA $5 \mathrm{ul}$ and Water, nuclease-free $18 \mu \mathrm{l}$ where total volume was $50 \mu \mathrm{l}$. Gently vortex the samples and spin down. PCR performed using the recommended thermal cycling conditions F: AGAGTTTGATCCTGGCTCAG R:GGTTACCTTGTTACGACTT

- PCR clean up to the PCR product using GeneJETTM PCR Purification Kit (Thermo K0701).

Added a 45ul of Binding Buffer to completed 
PCR mixture and Mix thoroughly. The mixture was transferred from step 1 to the GeneJETTM purification column and centrifugation for 30-60 $\mathrm{s}$ at $>12000 \mathrm{x} \mathrm{g}$. Discard the flow-through, then 100ul of Wash Buffer was added to the GeneJET ${ }^{\mathrm{TM}}$ purification column and centrifugation for 30-60 s. Discard the flow-through and the purification column back was placed into the collection tube, the purified DNA at $-20^{\circ} \mathrm{C}$. Finally sequencing to the PCR product was made on GATC Company by use ABI 3730xl DNA sequencer by using forward and reverse primers. Only by combining the traditional Sanger technology with the new 454 technologies, can genomes now be sequenced and analyzed in half the usual project time, with a considerable reduction in the number of coatings and gaps. In addition, considerable cost advantages now make genome sequencing with the 454 technology accessible to the research community.

\section{Optimization of culture conditions for enhanced wastewater treatment by most potent bacterial isolates}

The effect of various culture conditions such as $\mathrm{pH}$, temperature, inoculum size, and incubation period at different condition (static and shaker status) on wastewater treatment by the most potent bacterial strains was examined.

Control (raw wastewater without inoculation) was running with each experiments.

\section{Effect of different incubation temperature, $p H$ and inoculum size on wastewater treatment by two bacterial isolate}

In order to test the effect of different incubation temperature on the wastewater treatment process, the two bacterial isolates were allowed to grow on $500 \mathrm{ml}$ raw wastewater. The microbial isolates were incubated for 7 days at different $\mathrm{pH}$ values $(5,6,7,8$ and 9) a triplicate for each organism on each sample. Similarly, the effect of different incubation temperature 20, 25,
30,35 and $40^{\circ} \mathrm{C}$ on wastewater treatment was tested. Separately, the wastewater treatment percentages were evaluated under the effect of different bacterial inoculum sizes were applied as $0.5 \%, 1 \%, 2 \%$ and $3 \%(\mathrm{v} / \mathrm{v})$ in $500 \mathrm{ml}$ of wastewater samples.

At the end of each experiment, the following parameter were analyzed (COD, BOD, TS, TSS, TDS, $\mathrm{pH}$, Conductivity and Ammonia)

\section{Effect of different incubation period and incubation condition (static and shaking status) on wastewater treatment}

This experiment was carried out in order to investigate the effect of different incubation period and condition on wastewater treatment process. The two potent bacterial isolates were allowed to separately grow on $500 \mathrm{ml}$ of wastewater, allowed to grow at previous optimum $\mathrm{pH}$ value, incubation temperature and inoculum size for 24, 48, 72, 96, 120, 144 and 168 hours at static and shaking $(150 \mathrm{rpm})$ a triplicate for each organism on each sample to determine the best incubation conditions and time. At the end of experiment, the following parameters were analyzed (COD, BOD, TS, TSS, TDS, pH, Conductivity and Ammonia).

\section{Effect of different metals present in wastewater on growth of two potent isolates}

Wastewater containing different type of metal such as $\mathrm{Cr}, \mathrm{Pb}, \mathrm{Fe}, \mathrm{Zn}$ and $\mathrm{Cu}$. Therefore, it's important to detect the effect of this metal on microbial growth used in wastewater treatment process.

\section{Effect of different concentrations of single metals on microbial growth count}

Two most potent bacterial isolates were inoculated in $200 \mathrm{ml}$ of TSB containing different concentration of metals in single form and mixture $(\mathrm{Cr}, \mathrm{Pb}$, $\mathrm{Fe}, \mathrm{Zn}, \mathrm{Cu}$ applied as 5, 10 and $15 \mathrm{mg} / \mathrm{l}$ ) in separate conical flask. The flasks were incubated at $35^{\circ} \mathrm{C}$ for $48 \mathrm{~h}$. The ability of bacterial isolates to tolerate metal concentration were be detected by bacterial count at the end of experiment. 
Effect of different concentrations of metals mixture on wastewater treatment process by bacterial isolates

The optimum inoculum of each most potent bacterial isolates were inoculated in $500 \mathrm{ml}$ of wastewater containing different concentration of metal mixture $(\mathrm{Cr}, \mathrm{Pb}, \mathrm{Fe}, \mathrm{Cu} \& \mathrm{Zn}$ at 5, 10 and $15 \mathrm{mg} / \mathrm{l})$ and incubated at optimum previous condition. The metals reduction were detected by Plasma Emission Spectroscopy system and wastes reduction were detected by measuring COB, BOD, TSS and ammonia.

\section{Analyses of treated wastewater}

The values of $\mathrm{pH}$, TDS (Total Dissolved Solids), TSS (Total Suspended Solids), TS (Total Solid), COD (Chemical Oxygen Demand), BOD (Biological Oxygen Demand), ammonia and TOG (Total oil \& Grease) were measured for wastewater samples before and after the different treatments. The measures were carried out according to the standard methods recommended by FEW and APHA, 2012, Eugene, et al., 2012.

Metals were measured by Plasma Emission Spectroscopy. The equipment's used were ICP-OES 7300DV (Perkin Elmer, U.K), Microwave (Anton Paar, Europe) and Electronic balance (Sartouriu, Germany) according to FEW and APHA, 2012, ${ }^{22}$ th Edition, method No 3120B.

\section{Statistical Analysis}

Data were statistically analyzed by SPSS v17, one-way and two way analyses of variance (ANOVA) test were used for multiple sample comparison, when normality and homogeneity of variance were satisfied, followed by multiple comparison Tukey test.

\section{RESULTS}

\section{Samples}

The collected wastewater samples were undergo chemical analysis to detect their content before treatment as shown in Table 1. Data showed that the highest content of heavy metal especially $\mathrm{Pb}$ and $\mathrm{Fe}$ and total bacterial count were in shobra El-Khema plant. During this study, thirty-one bacterial isolates were isolated from three plant and classified as the following, eleven isolates from Abu Rawash, eleven isolates from El Tanqia and nine from Shobra ElKhema.

Thirty-one isolates were inoculated in MSO containing diesel oil as a sole carbon source. From this isolates, fifteen isolates have the ability to grow on MSO and classified as the following, four isolates from Abu Rawash, three isolates from El Tanqia and eight from Shobra El-Khema. Therefore, fifteen bacterial isolates inoculated in wastewater sample to select most potent bacterial isolates according to result of TSS, COD and BOD as shown in Table 2. According to the results of TSS, COD and BOD for different bacterial isolates which detected the best treatment, the bacterial isolates A4 and A5 were least can be compared by other isolates. Therefore, selected isolates A4 and A5 as most potent

The molecular identification based on 16S rRNA gene amplification showed that the bacterial strains A4 and A5 have similarity to Klebsiella pneumonia and Acinetobacter lwoffii, respectively. The topology of Klebsiella pneumonia and Acinetobacter lwoffii strains A4 and A5 was retrieved from the phylogenetic tree including various bacterial $16 \mathrm{~S}$ rRNA gene sequences of the common bacterial families (Fig.1). 
Table (1) : Chemical analysis and total bacterial count of the collected wastewater samples.

\begin{tabular}{|c|c|c|c|c|}
\hline $\begin{array}{c}\text { ParameterslSamlpe } \\
\text { types }\end{array}$ & Units & Abu Rawash & EITanqia El Sharqia & Shobra Elkhema \\
\hline pH & & $7.35 \pm 0.09$ & $7.33 \pm 0.09$ & $7.41 \pm 0.09$ \\
\hline Conductivity & phmos & $768 \pm 3$ & $1845 \pm 5.57$ & $846 \pm 6.08$ \\
\hline TDS & $\mathrm{ppm}$ & $461 \pm 1.15$ & $1107 \pm 3.46$ & $510 \pm 4.04$ \\
\hline TS & $\mathrm{ppm}$ & $709 \pm 3.21$ & $1408 \pm 8.14$ & $710 \pm 5$ \\
\hline TSS & $\mathrm{ppm}$ & $193 \pm 4.73$ & $200 \pm 2.65$ & $184 \pm 2.52$ \\
\hline Ammonia & $\mathrm{ppm}$ & $26.9 \pm 0.12$ & $32.3 \pm 0.58$ & $20.6 \pm 0$ \\
\hline $\mathbf{C O D}$ & $\mathrm{ppm}$ & $348 \pm 1.53$ & $502 \pm 2$ & $548 \pm 1.73$ \\
\hline $\mathbf{B O D}$ & $\mathrm{ppm}$ & $116 \pm 1.53$ & $244 \pm 3.51$ & $243 \pm 3.51$ \\
\hline TOG & $\mathrm{ppm}$ & $55 \pm 1.53$ & $58 \pm 2$ & $61 \pm 1$ \\
\hline $\mathbf{P b}$ & $\mathrm{ppm}$ & $0.0040 \pm 0.0001$ & $0.2051 \pm 0.0001$ & $2.1667 \pm 0.0012$ \\
\hline $\mathbf{C d}$ & $\mathrm{ppm}$ & $0.0000 \pm 0.0000$ & $0.0020 \pm 0.0000$ & $0.0030 \pm 0.0001$ \\
\hline $\mathbf{Z n}$ & $\mathrm{ppm}$ & $0.1167 \pm 0.0015$ & $0.3737 \pm 0.0012$ & $0.2430 \pm 0.0017$ \\
\hline $\mathbf{C u}$ & $\mathrm{ppm}$ & $0.0000 \pm 0.0000$ & $0.2760 \pm 0.0000$ & $0.0990 \pm 0.0000$ \\
\hline $\mathbf{N i}$ & $\mathrm{ppm}$ & $0.0050 \pm 0.0000$ & $0.0457 \pm 0.00115$ & $0.0400 \pm 0.0000$ \\
\hline $\mathbf{F e}$ & $\mathrm{ppm}$ & $0.4520 \pm 0.0000$ & $0.6700 \pm 0.0000$ & $1.8167 \pm 0.0116$ \\
\hline $\mathbf{C r}$ & $\mathrm{ppm}$ & $0.0080 \pm 0.0006$ & $0.2493 \pm 0.00058$ & $0.1080 \pm 0.0017$ \\
\hline $\begin{array}{c}\text { Total bacterial } \\
\text { count on TSA }\end{array}$ & $\mathrm{cell} / \mathrm{ml}$ & $26.2 * 10^{5} \pm 3.8 * 10^{3}$ & $11.4 * 10^{5} \pm 4.04 * 10^{2}$ & $62.1 * 10^{5} \pm 11.5 * 10^{3}$ \\
\hline $\begin{array}{c}\text { Total bacterial } \\
\text { count on MSO }\end{array}$ & $\mathrm{cell} / \mathrm{ml}$ & $3657 \pm 14$ & $3998 \pm 13$ & $4975 \pm 22$ \\
\hline
\end{tabular}

$C F U=$ Colony Forming Unit

ppm $=$ Part Per million

*All data represented means of three replica \pm Stander Deviation (SD)

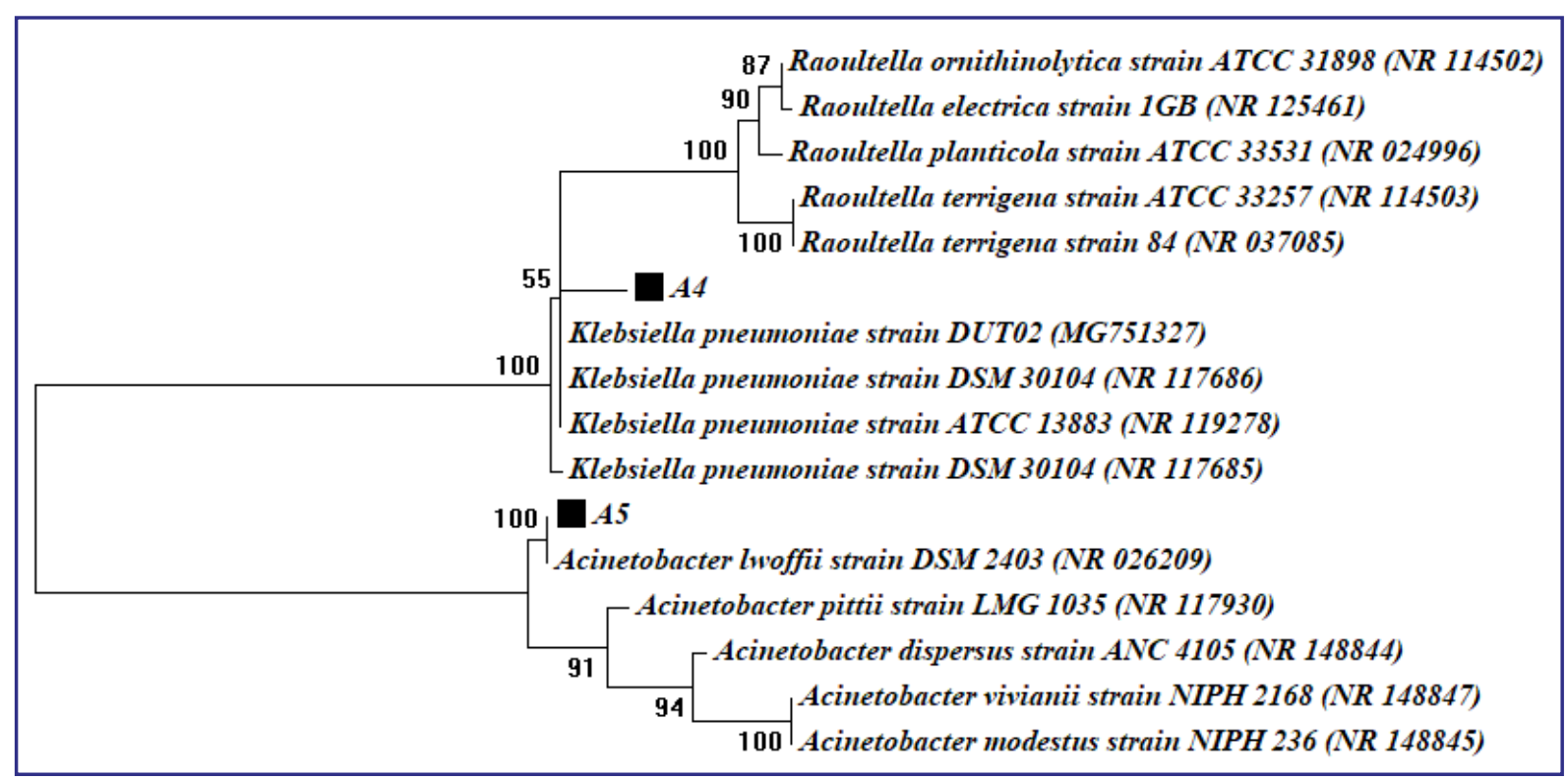

Fig. (1): Phylogenetic analysis of 16S rRNA sequences of the bacterial isolates with the sequences from NCBI. Symbol $\mathbf{m}$ refers to $16 \mathrm{~S}$ rRNA gene fragments retrieved from this study. The analysis was conducted with MEGA 6 using neighborjoining method. 
Table (2) : Selection of the most potent bacterial isolates.

\begin{tabular}{|c|c|c|c|c|c|}
\hline Sample & $\mathbf{p H}$ & $\mathbf{T S}(\mathbf{m g} / \mathbf{l})$ & TSS (mg/l) & COD (mg/l) & BOD (mg/l) \\
\hline Raw sample & $7.11 \pm 0.01$ & $810.3 \pm 7.2$ & $204.5 \pm 3.6$ & $438 \pm 2.1$ & $214 \pm 0.9$ \\
\hline Control & $7.1 \pm 0.15$ & $828.21 \pm 13.35$ & $56.39 \pm 3.12$ & $114.80 \pm 5.65$ & $54.38 \pm 0.78$ \\
\hline Isolate A1 & $8.0 \pm 0.21$ & $807.45 \pm 7.21$ & $40.28 \pm 2.13$ & $75.63 \pm 3.27$ & $36.25 \pm 1.19$ \\
\hline Isolate A2 & $7.82 \pm 0.12$ & $788.83 \pm 11.23$ & $24.17 \pm 5.29$ & $76.53 \pm 4.34$ & $36.25 \pm 2.18$ \\
\hline Isolate A3 & $8.21 \pm 0.09$ & $809.15 \pm 17.5$ & $48.34 \pm 2.12$ & $95.67 \pm 2.11$ & $45.32 \pm 4.76$ \\
\hline Isolate A4 & $7.63 \pm 0.13$ & $787.11 \pm 13.2$ & $16.11 \pm 1.23$ & $73.51 \pm 5.23$ & $35.25 \pm 1.57$ \\
\hline Isolate A5 & $7.93 \pm 0.23$ & $801.19 \pm 9.66$ & $32.22 \pm 6.53$ & $57.30 \pm 7.56$ & $27.19 \pm 1.23$ \\
\hline Isolate A6 & $7.77 \pm 0.14$ & $796.67 \pm 12.31$ & $40.28 \pm 7.29$ & $94.86 \pm 5.82$ & $45.32 \pm 6.11$ \\
\hline Isolate A7 & $7.91 \pm 0.05$ & $778.73 \pm 20.9$ & $19.08 \pm 5.26$ & $80.03 \pm 3.19$ & $29.20 \pm 7.23$ \\
\hline Isolate A8 & $8.36 \pm 0.21$ & $775.5 \pm 14.23$ & $28.20 \pm 6.17$ & $90.03 \pm 2.62$ & $42.29 \pm 2.11$ \\
\hline Isolate A9 & $8.19 \pm 0.17$ & $776.63 \pm 13.72$ & $25.18 \pm 1.23$ & $88.20 \pm 5.17$ & $27.19 \pm 1.25$ \\
\hline Isolate A10 & $8.2 \pm 0.07$ & $775.27 \pm 11.15$ & $28.20 \pm 0.9$ & $94.26 \pm 4.36$ & $44.31 \pm 4.73$ \\
\hline Isolate A11 & $8.05 \pm 0.13$ & $799.57 \pm 15.83$ & $40.28 \pm 4.75$ & $87.91 \pm 3.17$ & $41.29 \pm 6.12$ \\
\hline Isolate A12 & $8.02 \pm 0.05$ & $774.59 \pm 9.38$ & $32.06 \pm 3.17$ & $80.29 \pm 6.15$ & $33.23 \pm 2.57$ \\
\hline Isolate A13 & $8.11 \pm 0.13$ & $804.37 \pm 17.1$ & $44.31 \pm 7.85$ & $91.84 \pm 2.13$ & $43.30 \pm 0.9$ \\
\hline Isolate A14 & $7.83 \pm 0.18$ & $782.13 \pm 15.23$ & $20.14 \pm 3.22$ & $91.33 \pm 2.94$ & $43.30 \pm 1.13$ \\
\hline Isolate A15 & $7.69 \pm 0.12$ & $785.13 \pm 11.2$ & $22.15 \pm 4.21$ & $91.53 \pm 4.63$ & $59.20 \pm 3.5$ \\
\hline
\end{tabular}

*All data represented means of three replica \pm Stander Deviation (SD)

\section{Optimized factor affecting wastewater treatment} Effect of pH, temperature, and inoculum size on wastewater treatment process

Data of COD, BOD, TSS and ammonia for treated wastewater by two most potent bacterial isolates revealed that the maximum treated was recorded at $\mathrm{pH} 7$ and any increase or decrease in $\mathrm{pH}$ from the optimal value reduces the treatment process. Our result showed that COD, BOD, TSS and ammonia for wastewater treated by Klebsiella pneumonia and Acinetobacter lwoffii were $46.63 \pm 0.69$ and $43.53 \pm 0.65,21.97 \pm 0.33$ and $20.97 \pm 0.31,9.98 \pm 0.15$ and $8.99 \pm 0.13,29.76 \pm 0.44$ and $32.05 \pm 0.48$ respectively when compared with control (Table 3 ).

The results showed that the highest treatment values were found at temperature $35^{\circ} \mathrm{C}$ for both the two most potent bacterial isolates according to data of COD, BOD, TSS and ammonia value showed in Table 4 when compared to control. Data also showed that the maximum waste reduction in treated wastewater was achieved at inoculum size represented by $0.5 \%$ and $2 \%$ for Klebsiella pneumoniae and Acinetobacter lwoffii respectively (Table 5). 
Table (3) : Effect of different $p H$ values on the wastewater treatment process.

\begin{tabular}{|c|c|c|c|c|c|c|c|}
\hline Sample & Conditions & TS (mg/l) & TDS (mg/l) & COD (mg/l) & BOD (mg/l) & TSS (mg/l) & $\underset{(\mathrm{mg} / \mathrm{l})}{\text { Ammonia }}$ \\
\hline \multicolumn{2}{|c|}{ Raw sample } & $\begin{array}{c}820.13 \\
15.02\end{array}$ & $\begin{array}{c}552.81 \\
10.12\end{array}$ & $\begin{array}{c}441.03 \pm \\
7.05\end{array}$ & $\begin{array}{c}217.49 \\
4.43\end{array}$ & $\begin{array}{c}208.07 \pm \\
4.7\end{array}$ & $\begin{array}{c}24.58 \pm \\
0.62\end{array}$ \\
\hline \multirow{5}{*}{$\begin{array}{c}\text { Control at } \\
\text { different } \\
\text { initial } \\
\text { pH values }\end{array}$} & pH5 & $\begin{array}{c}949.41 \\
17.23\end{array}$ & $\begin{array}{c}839.74 \\
12.45\end{array}$ & $\begin{array}{c}84.47 \\
1.25\end{array}$ & $\begin{array}{c}40.94 \pm \\
0.61\end{array}$ & $\begin{array}{c}27.96 \pm \\
0.41\end{array}$ & $\begin{array}{c}32.55 \pm \\
0.48\end{array}$ \\
\hline & pH6 & $\begin{array}{c}908.68 \pm \\
16.88\end{array}$ & $\begin{array}{c}806.79 \\
11.96\end{array}$ & $\begin{array}{c}80.68 \\
1.2\end{array}$ & $\begin{array}{c}38.94 \\
0.58\end{array}$ & $\begin{array}{c}22.97 \\
0.34\end{array}$ & $\begin{array}{c}38.04 \\
0.56\end{array}$ \\
\hline & pH7 & $\begin{array}{c}608.03 \\
11.41\end{array}$ & $\begin{array}{c}539.19 \pm \\
7.99\end{array}$ & $\begin{array}{c}67.60 \pm \\
1.3\end{array}$ & $\begin{array}{c}32.95 \pm \\
0.49\end{array}$ & $\begin{array}{c}17.97 \\
0.27\end{array}$ & $\begin{array}{c}31.35 \\
0.53\end{array}$ \\
\hline & pH8 & $\begin{array}{c}679.42 \\
14.15\end{array}$ & $\begin{array}{c}600.10 \pm \\
8.9\end{array}$ & $\begin{array}{c}67.20 \\
1.92\end{array}$ & $\begin{array}{c}31.95 \pm \\
0.47\end{array}$ & $\begin{array}{c}19.97 \pm \\
0.3\end{array}$ & $\begin{array}{c}35.45 \\
0.53\end{array}$ \\
\hline & pH9 & $\begin{array}{c}846.75 \\
18.59\end{array}$ & $\begin{array}{c}752.87 \\
11.16\end{array}$ & $\begin{array}{c}66.10 \pm \\
0.98\end{array}$ & $\begin{array}{c}31.95 \\
0.47\end{array}$ & $\begin{array}{c}17.97 \pm \\
0.27\end{array}$ & $\begin{array}{c}34.65 \pm \\
0.51\end{array}$ \\
\hline \multirow{5}{*}{$\begin{array}{c}\text { K.pneumonia } \\
\text { at different } \\
\text { initial } \\
\text { pH values }\end{array}$} & pH5 & $\begin{array}{c}936.62 \pm \\
17.71\end{array}$ & $\begin{array}{c}832.75 \\
12.35\end{array}$ & $\begin{array}{c}68.50 \pm \\
1.02\end{array}$ & $\begin{array}{c}32.95 \pm \\
0.49\end{array}$ & $\begin{array}{c}21.97 \\
0.33\end{array}$ & $\begin{array}{c}33.35 \pm \\
0.49\end{array}$ \\
\hline & pH6 & $\begin{array}{c}878.67 \\
13.21\end{array}$ & $\begin{array}{c}802.79 \pm \\
11.9\end{array}$ & $\begin{array}{c}47.23 \pm \\
0.7\end{array}$ & $\begin{array}{c}22.97 \pm \\
0.34\end{array}$ & $\begin{array}{c}7.99 \pm \\
0.12\end{array}$ & $\begin{array}{c}33.85 \pm \\
0.50\end{array}$ \\
\hline & pH7 & $\begin{array}{c}629.61 \\
16.48\end{array}$ & $\begin{array}{c}560.16 \pm \\
8.3\end{array}$ & $\begin{array}{c}46.63 \pm \\
0.69\end{array}$ & $\begin{array}{c}21.97 \\
0.33\end{array}$ & $\begin{array}{c}9.98 \pm \\
0.15\end{array}$ & $\begin{array}{c}29.76 \pm \\
0.44\end{array}$ \\
\hline & pH8 & $\begin{array}{c}647.74 \\
10.83\end{array}$ & $\begin{array}{c}584.12 \\
8.66\end{array}$ & $\begin{array}{c}55.72 \\
0.83\end{array}$ & $\begin{array}{c}26.96 \pm \\
0.40\end{array}$ & $\begin{array}{c}11.98 \\
0.18\end{array}$ & $\begin{array}{c}36.15 \\
0.54\end{array}$ \\
\hline & pH9 & $\begin{array}{c}829.53 \pm \\
13.2\end{array}$ & $\begin{array}{c}748.87 \\
11.1\end{array}$ & $\begin{array}{c}58.61 \pm \\
0.87\end{array}$ & $\begin{array}{c}27.96 \pm \\
0.41\end{array}$ & $\begin{array}{c}15.98 \pm \\
0.24\end{array}$ & $\begin{array}{c}34.75 \pm \\
0.52\end{array}$ \\
\hline \multirow{5}{*}{$\begin{array}{c}\text { A.lwoffii at } \\
\text { different } \\
\text { initial } \\
\text { pH values }\end{array}$} & pH5 & $\begin{array}{c}931.55 \\
15.69\end{array}$ & $\begin{array}{c}833.74 \\
12.36\end{array}$ & $\begin{array}{c}59.81 \\
0.89\end{array}$ & $\begin{array}{c}28.96 \\
0.43\end{array}$ & $\begin{array}{c}19.97 \\
0.3\end{array}$ & $\begin{array}{c}33.15 \pm \\
0.49\end{array}$ \\
\hline & pH6 & $\begin{array}{c}883.42 \\
15.45\end{array}$ & $\begin{array}{c}798.80 \\
11.84\end{array}$ & $\begin{array}{c}55.62 \pm \\
0.82\end{array}$ & $\begin{array}{c}26.96 \pm \\
0.40\end{array}$ & $\begin{array}{c}9.98 \pm \\
0.15\end{array}$ & $\begin{array}{c}39.64 \pm \\
0.59\end{array}$ \\
\hline & pH7 & $\begin{array}{c}610.03 \\
9.69\end{array}$ & $\begin{array}{c}553.17 \pm \\
8.2\end{array}$ & $\begin{array}{c}43.53 \pm \\
0.65\end{array}$ & $\begin{array}{c}20.97 \\
0.31\end{array}$ & $\begin{array}{c}8.99 \pm \\
0.13\end{array}$ & $\begin{array}{c}32.05 \\
0.48\end{array}$ \\
\hline & pH8 & $\begin{array}{c}663.94 \pm \\
15.62\end{array}$ & $\begin{array}{c}590.11 \pm \\
8.75\end{array}$ & $\begin{array}{c}49.73 \pm \\
0.74\end{array}$ & $\begin{array}{c}23.96 \pm \\
0.36\end{array}$ & $\begin{array}{c}12.98 \pm \\
0.19\end{array}$ & $\begin{array}{c}37.34 \\
0.55\end{array}$ \\
\hline & pH9 & $\begin{array}{c}832.61 \pm \\
18.36\end{array}$ & $\begin{array}{c}749.87 \\
11.12\end{array}$ & $\begin{array}{c}64.50 \pm \\
0.96\end{array}$ & $\begin{array}{c}30.95 \pm \\
0.46\end{array}$ & $\begin{array}{c}17.97 \pm \\
0.27\end{array}$ & $\begin{array}{c}34.75 \pm \\
0.52\end{array}$ \\
\hline
\end{tabular}


Table (4) : Effect of different incubation temperatures on the wastewater treatment process.

\begin{tabular}{|c|c|c|c|c|c|c|c|}
\hline Sample & Condition & TS (mg/l) & TDS (mg/l) & COD (mg/l) & BOD (mg/l) & TSS (mg/l) & $\underset{(\mathrm{mg} / \mathrm{l})}{\text { Ammonia }}$ \\
\hline \multicolumn{2}{|c|}{ Raw sample } & $\begin{array}{c}841.34 \\
15.38\end{array}$ & $\begin{array}{c}576.13 \\
8.54\end{array}$ & $\begin{array}{c}463.80 \pm \\
6.88\end{array}$ & $\begin{array}{c}221.67 \pm \\
3.29\end{array}$ & $\begin{array}{c}194.71 \pm \\
2.89\end{array}$ & $\begin{array}{c}18.52 \pm \\
0.27\end{array}$ \\
\hline \multirow{5}{*}{$\begin{array}{c}\text { Control at } \\
\text { different } \\
\text { incubation } \\
\text { temperatures }\end{array}$} & $20^{\circ} \mathrm{C}$ & $\begin{array}{c}736.64 \\
14.32\end{array}$ & $\begin{array}{c}654.02 \pm \\
9.7\end{array}$ & $\begin{array}{c}84.37 \\
1.25\end{array}$ & $\begin{array}{c}39.94 \pm \\
0.59\end{array}$ & $\begin{array}{c}19.97 \\
0.3\end{array}$ & $\begin{array}{c}38.78 \\
1.15\end{array}$ \\
\hline & $25^{\circ} \mathrm{C}$ & $\begin{array}{c}623.82 \pm \\
9.25\end{array}$ & $\begin{array}{c}691.96 \pm \\
10.26\end{array}$ & $\begin{array}{c}82.72 \pm \\
2.71\end{array}$ & $\begin{array}{c}38.87 \\
1.29\end{array}$ & $\begin{array}{c}20.97 \pm \\
0.31\end{array}$ & $\begin{array}{c}37.54 \pm \\
0.56\end{array}$ \\
\hline & $30^{\circ} \mathrm{C}$ & $\begin{array}{c}764.54 \\
11.39\end{array}$ & $\begin{array}{c}685.97 \\
10.17\end{array}$ & $\begin{array}{c}80.63 \pm \\
1.2\end{array}$ & $\begin{array}{c}37.94 \pm \\
0.56\end{array}$ & $\begin{array}{c}21.97 \\
0.33\end{array}$ & $\begin{array}{c}43.93 \\
0.65\end{array}$ \\
\hline & $35^{\circ} \mathrm{C}$ & $\begin{array}{c}771.32 \pm \\
14.54\end{array}$ & $\begin{array}{c}685.97 \pm \\
10.17\end{array}$ & $\begin{array}{c}73.09 \\
1.08\end{array}$ & $\begin{array}{c}34.95 \pm \\
0.52\end{array}$ & $\begin{array}{c}19.97 \\
0.3\end{array}$ & $\begin{array}{c}47.03 \\
0.70\end{array}$ \\
\hline & $40^{\circ} \mathrm{C}$ & $\begin{array}{c}767.27 \\
13.46\end{array}$ & $\begin{array}{c}687.96 \pm \\
10.20\end{array}$ & $\begin{array}{c}80.08 \pm \\
1.19\end{array}$ & $\begin{array}{c}37.94 \pm \\
0.56\end{array}$ & $\begin{array}{c}15.98 \\
0.24\end{array}$ & $\begin{array}{c}37.34 \\
0.55\end{array}$ \\
\hline \multirow{5}{*}{$\begin{array}{c}\text { K.pneumonia } \\
\text { at different } \\
\text { incubation } \\
\text { temperatures }\end{array}$} & $20^{\circ} \mathrm{C}$ & $\begin{array}{c}660.87 \\
11.05\end{array}$ & $\begin{array}{c}592.11 \\
8.78\end{array}$ & $\begin{array}{c}77.78 \\
1.15\end{array}$ & $\begin{array}{c}36.94 \\
0.55\end{array}$ & $\begin{array}{c}15.98 \pm \\
0.24\end{array}$ & $\begin{array}{c}36.20 \pm \\
0.98\end{array}$ \\
\hline & $25^{\circ} \mathrm{C}$ & $\begin{array}{c}615.12 \\
13.94\end{array}$ & $\begin{array}{c}667.00 \pm \\
9.89\end{array}$ & $\begin{array}{c}69.10 \pm \\
1.02\end{array}$ & $\begin{array}{c}33.5 \pm \\
0.94\end{array}$ & $\begin{array}{c}17.97 \pm \\
0.27\end{array}$ & $\begin{array}{c}34.05 \pm \\
0.50\end{array}$ \\
\hline & $30^{\circ} \mathrm{C}$ & $\begin{array}{c}681.78 \\
15.03\end{array}$ & $\begin{array}{c}605.59 \pm \\
8.98\end{array}$ & $\begin{array}{c}45.78 \pm \\
1.68\end{array}$ & $\begin{array}{c}21.97 \\
0.33\end{array}$ & $\begin{array}{c}15.48 \\
0.23\end{array}$ & $\begin{array}{c}35.05 \\
0.52\end{array}$ \\
\hline & $35^{\circ} \mathrm{C}$ & $\begin{array}{c}699.57 \pm \\
10.44\end{array}$ & $\begin{array}{c}638.04 \\
9.46\end{array}$ & $\begin{array}{c}40.14 \\
0.6\end{array}$ & $\begin{array}{c}18.97 \\
0.28\end{array}$ & $\begin{array}{c}9.98 \pm \\
0.15\end{array}$ & $\begin{array}{c}37.84 \\
056\end{array}$ \\
\hline & $40^{\circ} \mathrm{C}$ & $\begin{array}{c}691.87 \\
13.96\end{array}$ & $\begin{array}{c}618.07 \\
9.16\end{array}$ & $\begin{array}{c}48.63 \pm \\
0.72\end{array}$ & $\begin{array}{c}22.97 \pm \\
0.34\end{array}$ & $\begin{array}{c}13.98 \\
0.21\end{array}$ & $\begin{array}{c}30.15 \pm \\
0.45\end{array}$ \\
\hline \multirow{5}{*}{$\begin{array}{c}\text { A.lwoffii at } \\
\text { different } \\
\text { incubation } \\
\text { temperatures }\end{array}$} & $20^{\circ} \mathrm{C}$ & $\begin{array}{c}783.78 \pm \\
15.5\end{array}$ & $\begin{array}{c}695.95 \pm \\
10.32\end{array}$ & $\begin{array}{c}78.18 \\
1.16\end{array}$ & $\begin{array}{c}36.94 \\
0.55\end{array}$ & $\begin{array}{c}19.97 \pm \\
0.30\end{array}$ & $\begin{array}{c}45.83 \pm \\
0.68\end{array}$ \\
\hline & $25^{\circ} \mathrm{C}$ & $\begin{array}{c}720.17 \\
16.98\end{array}$ & $\begin{array}{c}777.83 \\
11.53\end{array}$ & $\begin{array}{c}71.79 \pm \\
1.06\end{array}$ & $\begin{array}{c}34.89 \pm \\
0.67\end{array}$ & $\begin{array}{c}18.97 \\
0.28\end{array}$ & $\begin{array}{c}39.44 \pm \\
0.58\end{array}$ \\
\hline & $30^{\circ} \mathrm{C}$ & $\begin{array}{c}792.87 \\
15.65\end{array}$ & $\begin{array}{c}708.93 \\
10.51\end{array}$ & $\begin{array}{c}63.37 \pm \\
0.94\end{array}$ & $\begin{array}{c}29.95 \pm \\
0.44\end{array}$ & $\begin{array}{c}15.98 \\
0.24\end{array}$ & $\begin{array}{c}49.92 \\
0.74\end{array}$ \\
\hline & $35^{\circ} \mathrm{C}$ & $\begin{array}{c}816.11 \\
17.24\end{array}$ & $\begin{array}{c}733.90 \\
10.88\end{array}$ & $\begin{array}{c}45.43 \pm \\
0.67\end{array}$ & $\begin{array}{c}20.97 \pm \\
0.31\end{array}$ & $\begin{array}{c}9.98 \pm \\
0.15\end{array}$ & $\begin{array}{c}46.03 \pm \\
0.68\end{array}$ \\
\hline & $40^{\circ} \mathrm{C}$ & $\begin{array}{c}844.03 \pm \\
14.78\end{array}$ & $\begin{array}{c}757.86 \pm \\
11.23\end{array}$ & $\begin{array}{c}58.91 \pm \\
2.87\end{array}$ & $\begin{array}{c}27.96 \pm \\
0.41\end{array}$ & $\begin{array}{c}16.97 \pm \\
0.25\end{array}$ & $\begin{array}{c}43.53 \pm \\
0.65\end{array}$ \\
\hline
\end{tabular}


Table (5) : Effect of different inoculum size on treatment process.

\begin{tabular}{|c|c|c|c|c|c|c|c|}
\hline \multicolumn{2}{|c|}{ Sample type } & TS (mg/l) & $\begin{array}{c}\text { TDS } \\
(\mathrm{mg} / \mathrm{l})\end{array}$ & $\begin{array}{c}\text { COD } \\
(\mathrm{mg} / \mathrm{l})\end{array}$ & $\begin{array}{c}\text { BOD } \\
(\mathrm{mg} / \mathrm{l})\end{array}$ & $\begin{array}{c}\text { TSS } \\
(\mathrm{mg} / \mathrm{l})\end{array}$ & $\begin{array}{c}\text { Ammonia } \\
(\mathrm{mg} / \mathrm{l})\end{array}$ \\
\hline \multicolumn{2}{|c|}{ Raw water } & $\begin{array}{c}841.34 \\
15.38\end{array}$ & $\begin{array}{c}576.13 \pm \\
8.54\end{array}$ & $\begin{array}{c}463.80 \pm \\
6.88\end{array}$ & $\begin{array}{c}259.61 \pm \\
3.85\end{array}$ & $\begin{array}{c}194.71 \pm \\
2.89\end{array}$ & $\begin{array}{c}18.52 \\
0.27\end{array}$ \\
\hline \multicolumn{2}{|c|}{ Control } & $\begin{array}{c}775.35 \\
13.6\end{array}$ & $\begin{array}{c}690.96 \pm \\
10.24\end{array}$ & $\begin{array}{c}70.39 \pm \\
1.04\end{array}$ & $\begin{array}{c}38.94 \pm \\
0.58\end{array}$ & $\begin{array}{c}20.97 \pm \\
0.31\end{array}$ & $\begin{array}{c}38.04 \\
0.56\end{array}$ \\
\hline \multirow{4}{*}{ 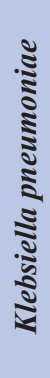 } & $\begin{array}{c}\text { Inoculum } \\
0.5 \%\end{array}$ & $\begin{array}{c}711.38 \\
12.83\end{array}$ & $\begin{array}{c}642.03 \\
9.52\end{array}$ & $\begin{array}{c}39.44 \\
0.58\end{array}$ & $\begin{array}{c}21.97 \\
0.33\end{array}$ & $\begin{array}{c}9.98 \pm \\
0.15\end{array}$ & $\begin{array}{c}36.94 \\
0.55\end{array}$ \\
\hline & $\begin{array}{c}\text { Inoculum } \\
1 \%\end{array}$ & $\begin{array}{c}711.38 \\
12.83\end{array}$ & $\begin{array}{c}641.03 \\
9.5\end{array}$ & $\begin{array}{c}40.04 \\
0.59\end{array}$ & $\begin{array}{c}21.97 \\
0.33\end{array}$ & $\begin{array}{c}10.98 \pm \\
0.16\end{array}$ & $\begin{array}{c}37.94 \\
0.56\end{array}$ \\
\hline & $\begin{array}{c}\text { Inoculum } \\
2 \%\end{array}$ & $\begin{array}{c}719.44 \\
11.34\end{array}$ & $\begin{array}{c}650.02 \\
9.64\end{array}$ & $\begin{array}{c}42.04 \\
0.62\end{array}$ & $\begin{array}{c}22.97 \\
0.34\end{array}$ & $\begin{array}{c}12.98 \pm \\
0.19\end{array}$ & $\begin{array}{c}39.04 \\
0.58\end{array}$ \\
\hline & $\begin{array}{c}\text { Inoculum } \\
\mathbf{3} \%\end{array}$ & $\begin{array}{c}710.68 \\
10.61\end{array}$ & $\begin{array}{c}647.03 \pm \\
9.59\end{array}$ & $\begin{array}{c}42.94 \\
0.64\end{array}$ & $\begin{array}{c}23.96 \pm \\
0.36\end{array}$ & $\begin{array}{c}10.98 \pm \\
0.16\end{array}$ & $\begin{array}{c}39.04 \\
0.58\end{array}$ \\
\hline \multirow{4}{*}{ 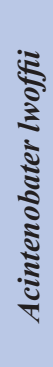 } & $\begin{array}{c}\text { Inoculum } \\
0.5 \%\end{array}$ & $\begin{array}{c}787.80 \pm \\
13.51\end{array}$ & $\begin{array}{c}711.93 \\
10.55\end{array}$ & $\begin{array}{c}48.23 \\
0.71\end{array}$ & $\begin{array}{c}26.96 \pm \\
0.4\end{array}$ & $\begin{array}{c}11.98 \pm \\
0.18\end{array}$ & $\begin{array}{c}40.14 \\
0.6\end{array}$ \\
\hline & $\begin{array}{c}\text { Inoculum } \\
1 \%\end{array}$ & $\begin{array}{c}801.26 \pm \\
13.46\end{array}$ & $\begin{array}{c}726.91 \\
10.78\end{array}$ & $\begin{array}{c}45.03 \pm \\
0.67\end{array}$ & $\begin{array}{c}24.96 \pm \\
0.37\end{array}$ & $\begin{array}{c}9.98 \pm \\
0.15\end{array}$ & $\begin{array}{c}43.14 \pm \\
0.64\end{array}$ \\
\hline & $\begin{array}{c}\text { Inoculum } \\
2 \%\end{array}$ & $\begin{array}{c}798.55 \\
12.02\end{array}$ & $\begin{array}{c}729.90 \\
10.82\end{array}$ & $\begin{array}{c}43.14 \pm \\
0.60\end{array}$ & $\begin{array}{c}23.96 \pm \\
0.36\end{array}$ & $\begin{array}{c}8.99 \pm \\
0.13\end{array}$ & $\begin{array}{c}41.64 \\
0.62\end{array}$ \\
\hline & $\begin{array}{c}\text { Inoculum } \\
3 \%\end{array}$ & $\begin{array}{c}820.83 \pm \\
17.74\end{array}$ & $\begin{array}{c}733.90 \pm \\
10.88\end{array}$ & $\begin{array}{c}42.94 \pm \\
0.64\end{array}$ & $\begin{array}{c}23.96 \pm \\
0.33\end{array}$ & $\begin{array}{c}13.98 \pm \\
0.21\end{array}$ & $\begin{array}{c}42.14 \pm \\
0.6\end{array}$ \\
\hline
\end{tabular}

\section{Effect of shaking and static condition at different incubation period}

The wastewater treatment process capacity of two potent bacterial isolates was estimated under shaking and static state at different incubation time and at optimum temperature, $\mathrm{pH}$ and inoculum size for each isolate. Time is a critical factor in treatment process in a large scale. Therefore, shaking condition was favorable for treatment process compared to static condition and the minimum time with accepted result was at $48 \mathrm{~h}$, where the additional time meaning higher cost and space of wastewater plants.
The higher ability of the two most potent bacterial strains for wastewater treatment in shaking condition compared to static condition suggest that shaking status is favorable to enhance bacterial biomass and oxygen transfer between bacterial cells and the surrounding substrates. By increasing time of treatment process, data showed that static condition was favorable for treatment compared to shaking, this may be due to bacterial cell enter in death phase and the highest treatment in static regarded to settling process (Table 6). 
Organic Compounds and Inorganic Metals Removal from Wastewater Using Klebsiella pneumoniae and Acinetobacter lwoffii (201)

Table (6) : Effect of static and shaking state at different incubation time on wastewater treatment.

\begin{tabular}{|c|c|c|c|c|c|c|c|c|c|}
\hline & \multirow{2}{*}{$\begin{array}{l}\text { Time } \\
\text { (h) }\end{array}$} & \multicolumn{2}{|c|}{ COD } & \multicolumn{2}{|c|}{ BOD } & \multicolumn{2}{|c|}{ TSS } & \multicolumn{2}{|c|}{ ammonia } \\
\hline & & Static & Shaker & Static & Shaker & Static & Shaker & Static & Shaker \\
\hline \multirow{8}{*}{$\frac{\overline{0}}{\grave{\theta}}$} & zero & $\begin{array}{c}449.13 \pm \\
8.94\end{array}$ & $\begin{array}{c}449.13 \pm \\
8.94\end{array}$ & $\begin{array}{c}267.94 \\
5.97\end{array}$ & $\begin{array}{c}267.94 \pm \\
5.97\end{array}$ & $\begin{array}{c}246.68 \\
\pm 5.52 \\
\end{array}$ & $\begin{array}{c}246.68 \\
\pm 5.52 \\
\end{array}$ & $\begin{array}{c}23.01 \\
0.45\end{array}$ & $\begin{array}{c}23.01 \\
0.45\end{array}$ \\
\hline & 24 & $\begin{array}{r}112.01 \pm \\
2.65\end{array}$ & $\begin{array}{c}98.85 \pm \\
2.57\end{array}$ & $\begin{array}{c}64.78 \pm \\
1.57\end{array}$ & $\begin{array}{c}56.68 \pm \\
1.53\end{array}$ & $\begin{array}{c}49.59 \pm \\
1.51\end{array}$ & $\begin{array}{c}54.65 \pm \\
1.52\end{array}$ & $\begin{array}{c}22.98 \pm \\
0.42\end{array}$ & $\begin{array}{c}11.74 \pm \\
0.22\end{array}$ \\
\hline & 48 & $\begin{array}{c}90.75 \pm \\
2.54\end{array}$ & $\begin{array}{c}95.81 \\
2.56\end{array}$ & $\begin{array}{c}52.63 \\
1.52\end{array}$ & $\begin{array}{c}54.65 \pm \\
1.51\end{array}$ & $\begin{array}{l}33.39 \\
\pm 1.51\end{array}$ & $\begin{array}{c}50.60 \pm \\
1.51\end{array}$ & $\begin{array}{c}24.60 \pm \\
0.46\end{array}$ & $\begin{array}{c}13.06 \pm \\
0.24\end{array}$ \\
\hline & 72 & $\begin{array}{c}81.64 \pm \\
2.51\end{array}$ & $\begin{array}{c}83.67 \pm \\
2.52\end{array}$ & $\begin{array}{r}46.56 \pm \\
1.5 \\
\end{array}$ & $\begin{array}{c}47.57 \pm \\
1.5 \\
\end{array}$ & $\begin{array}{c}26.31 \pm \\
1.54\end{array}$ & $\begin{array}{c}46.56 \pm \\
1.5\end{array}$ & $\begin{array}{c}25.81 \pm \\
0.48\end{array}$ & $\begin{array}{r}10.53 \pm \\
0.2\end{array}$ \\
\hline & 96 & $\begin{array}{c}78.60 \pm \\
2.51\end{array}$ & $\begin{array}{c}81.64 \pm \\
2.51\end{array}$ & $\begin{array}{c}40.48 \pm \\
1.5\end{array}$ & $\begin{array}{r}42.51 \pm \\
1.5 \\
\end{array}$ & $\begin{array}{c}24.28 \pm \\
1.55\end{array}$ & $\begin{array}{c}39.47 \pm \\
1.5\end{array}$ & $\begin{array}{c}28.65 \pm \\
0.54\end{array}$ & $\begin{array}{c}9.51 \pm \\
0.19\end{array}$ \\
\hline & 120 & $\begin{array}{c}75.57 \pm \\
2.5\end{array}$ & $\begin{array}{c}83.67 \pm \\
2.52\end{array}$ & $\begin{array}{r}38.46 \pm \\
1.5\end{array}$ & $\begin{array}{c}43.52 \\
1.5\end{array}$ & $\begin{array}{c}22.26 \pm \\
1.56\end{array}$ & $\begin{array}{c}36.43 \pm \\
1.5\end{array}$ & $\begin{array}{c}33.71 \pm \\
0.64\end{array}$ & $\begin{array}{c}8.30 \pm \\
0.17\end{array}$ \\
\hline & 144 & $\begin{array}{c}75.57 \pm \\
2.5 \\
\end{array}$ & $\begin{array}{c}86.70 \pm \\
2.55\end{array}$ & $\begin{array}{c}38.46 \pm \\
1.50\end{array}$ & $\begin{array}{c}44.53 \pm \\
1.51\end{array}$ & $\begin{array}{c}20.74 \pm \\
1.57\end{array}$ & $\begin{array}{c}32.38 \pm \\
1.51\end{array}$ & $\begin{array}{c}35.63 \pm \\
0.68\end{array}$ & $\begin{array}{c}7.19 \pm \\
0.16\end{array}$ \\
\hline & 168 & $\begin{array}{c}73.54 \pm \\
2.5\end{array}$ & $\begin{array}{c}86.70 \pm \\
2.71\end{array}$ & $\begin{array}{c}37.44 \pm \\
1.5\end{array}$ & $\begin{array}{c}44.53 \\
1.65\end{array}$ & $\begin{array}{c}20.23 \pm \\
1.57\end{array}$ & $\begin{array}{c}29.35 \pm \\
1.23\end{array}$ & $\begin{array}{c}39.07 \\
0.75\end{array}$ & $\begin{array}{c}6.78 \pm \\
0.17\end{array}$ \\
\hline \multirow{8}{*}{ 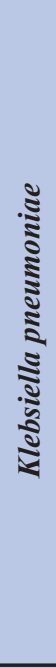 } & zero & $\begin{array}{c}449.13 \pm \\
8.94\end{array}$ & $\begin{array}{c}449.13 \pm \\
8.94\end{array}$ & $\begin{array}{c}267.94 \pm \\
5.97\end{array}$ & $\begin{array}{c}267.94 \pm \\
5.97\end{array}$ & $\begin{array}{c}246.68 \\
\pm 5.52\end{array}$ & $\begin{array}{c}246.68 \\
\pm 5.52\end{array}$ & $\begin{array}{c}23.01 \\
0.45\end{array}$ & $\begin{array}{c}23.01 \\
0.45\end{array} \pm$ \\
\hline & 24 & $\begin{array}{c}129.94 \pm \\
4.91\end{array}$ & $\begin{array}{c}67.17 \pm \\
3.83\end{array}$ & $\begin{array}{c}75.26 \pm \\
2.4 \\
\end{array}$ & $\begin{array}{c}38.81 \pm \\
1.73\end{array}$ & $\begin{array}{c}47.26 \pm \\
2.96\end{array}$ & $\begin{array}{c}41.18 \pm \\
2.87\end{array}$ & $\begin{array}{c}23.62 \pm \\
0.57\end{array}$ & $\begin{array}{c}12.89 \pm \\
0.35\end{array}$ \\
\hline & 48 & $\begin{array}{c}106.65 \pm \\
4.49\end{array}$ & $\begin{array}{c}61.10 \pm \\
3.73\end{array}$ & $\begin{array}{c}62.10 \pm \\
2.15\end{array}$ & $\begin{array}{c}34.77 \\
1.66\end{array}$ & $\begin{array}{c}20.94 \pm \\
2.58\end{array}$ & $\begin{array}{c}36.12 \\
2.79\end{array}$ & $\begin{array}{c}25.14 \pm \\
0.6\end{array}$ & $\begin{array}{c}11.27 \\
0.31\end{array}$ \\
\hline & 72 & $\begin{array}{c}58.06 \pm \\
3.68\end{array}$ & $\begin{array}{c}54.01 \\
3.62\end{array}$ & $\begin{array}{c}33.75 \pm \\
1.64\end{array}$ & $\begin{array}{c}30.72 \pm \\
1.59\end{array}$ & $\begin{array}{c}15.88 \pm \\
2.51\end{array}$ & $\begin{array}{c}32.07 \\
2.73\end{array}$ & $\begin{array}{c}26.25 \pm \\
0.62\end{array}$ & $\begin{array}{c}10.26 \pm \\
0.29\end{array}$ \\
\hline & 96 & $\begin{array}{c}43.89 \pm \\
3.47 \\
\end{array}$ & $\begin{array}{c}58.06 \pm \\
3.68\end{array}$ & $\begin{array}{c}22.62 \pm \\
1.46 \\
\end{array}$ & $\begin{array}{c}29.70 \pm \\
1.58\end{array}$ & $\begin{array}{c}10.81 \pm \\
2.45\end{array}$ & $\begin{array}{c}30.05 \pm \\
2.7 \\
\end{array}$ & $\begin{array}{c}30.81 \pm \\
0.72\end{array}$ & $\begin{array}{c}7.32 \pm \\
0.24 \\
\end{array}$ \\
\hline & 120 & $\begin{array}{c}42.88 \pm \\
3.45\end{array}$ & $\begin{array}{c}62.11 \pm \\
3.75\end{array}$ & $\begin{array}{c}21.60 \pm \\
1.45\end{array}$ & $\begin{array}{c}31.73 \pm \\
1.61\end{array}$ & $\begin{array}{c}9.80 \pm \\
2.44\end{array}$ & $\begin{array}{c}26.00 \pm \\
2.65\end{array}$ & $\begin{array}{c}33.34 \pm \\
0.77\end{array}$ & $\begin{array}{c}5.91 \pm \\
0.21\end{array}$ \\
\hline & 144 & $\begin{array}{c}41.86 \pm \\
3.44\end{array}$ & $\begin{array}{l}69.20 \\
\pm 3.86 \\
\end{array}$ & $\begin{array}{c}21.60 \pm \\
1.45\end{array}$ & $\begin{array}{c}35.78 \pm \\
1.68\end{array}$ & $\begin{array}{c}9.80 \pm \\
2.44\end{array}$ & $\begin{array}{c}18.91 \\
2.55\end{array} \pm$ & $\begin{array}{c}34.56 \pm \\
0.79\end{array}$ & $\begin{array}{c}2.16 \pm \\
0.14\end{array}$ \\
\hline & 168 & $\begin{array}{c}40.65 \pm \\
3.42\end{array}$ & $\begin{array}{c}70.21 \\
3.87\end{array}$ & $\begin{array}{c}20.59 \\
1.43\end{array}$ & $\begin{array}{c}35.78 \pm \\
1.68\end{array}$ & $\begin{array}{c}9.80 \pm \\
2.44\end{array}$ & $\begin{array}{c}16.89 \\
2.52\end{array}$ & $\begin{array}{c}36.68 \pm \\
0.84\end{array}$ & $\begin{array}{c}1.86 \pm \\
0.14\end{array}$ \\
\hline \multirow{8}{*}{ 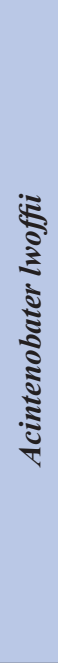 } & zero & $\begin{array}{c}449.13 \pm \\
8.94\end{array}$ & $\begin{array}{c}449.13 \pm \\
8.94\end{array}$ & $\begin{array}{c}267.94 \pm \\
5.97\end{array}$ & $\begin{array}{c}267.94 \pm \\
5.97 \\
\end{array}$ & $\begin{array}{c}246.68 \\
\pm 5.52 \\
\end{array}$ & $\begin{array}{c}246.68 \\
\pm 5.52 \\
\end{array}$ & $\begin{array}{c}23.01 \pm \\
0.45\end{array}$ & $\begin{array}{c}23.01 \\
0.45\end{array}$ \\
\hline & 24 & $\begin{array}{c}137.36 \pm \\
4.54\end{array}$ & $\begin{array}{c}89.78 \pm \\
3.67\end{array}$ & $\begin{array}{c}79.47 \\
2.25\end{array}$ & $\begin{array}{c}52.14 \\
1.72\end{array}$ & $\begin{array}{c}43.94 \pm \\
1.71\end{array}$ & $\begin{array}{c}40.91 \\
1.66\end{array}$ & $\begin{array}{c}24.16 \pm \\
0.48\end{array}$ & $\begin{array}{c}12.28 \pm \\
0.24\end{array}$ \\
\hline & 48 & $\begin{array}{c}87.75 \pm \\
3.63\end{array}$ & $\begin{array}{c}76.62 \pm \\
3.44\end{array}$ & $\begin{array}{c}51.13 \pm \\
1.7\end{array}$ & $\begin{array}{c}44.04 \pm \\
1.56 \\
\end{array}$ & $\begin{array}{c}5.47 \pm \\
1.11\end{array}$ & $\begin{array}{c}28.76 \pm \\
1.45\end{array}$ & $\begin{array}{c}25.17 \pm \\
0.46\end{array}$ & $\begin{array}{c}11.14 \pm \\
0.36\end{array}$ \\
\hline & 72 & $\begin{array}{c}50.30 \pm \\
3.01\end{array}$ & $\begin{array}{c}56.37 \pm \\
3.1\end{array}$ & $\begin{array}{c}28.86 \pm \\
1.29\end{array}$ & $\begin{array}{c}32.91 \\
1.36\end{array}$ & $\begin{array}{c}3.45 \pm \\
1.08\end{array}$ & $\begin{array}{c}21.67 \\
1.34\end{array}$ & $\begin{array}{c}26.86 \pm \\
0.5\end{array}$ & $8.47 \pm 0.4$ \\
\hline & 96 & $\begin{array}{c}41.18 \pm \\
2.87\end{array}$ & $\begin{array}{c}47.26 \pm \\
2.96\end{array}$ & $\begin{array}{c}20.76 \pm \\
1.16\end{array}$ & $\begin{array}{c}23.80 \pm \\
1.21\end{array}$ & $\begin{array}{c}3.45 \pm \\
1.08\end{array}$ & $\begin{array}{c}19.65 \pm \\
1.31\end{array}$ & $\begin{array}{c}31.72 \pm \\
0.62\end{array}$ & $\begin{array}{c}3.71 \pm \\
0.43\end{array}$ \\
\hline & 120 & $\begin{array}{c}40.17 \pm \\
2.85\end{array}$ & $\begin{array}{c}54.35 \pm \\
3.07\end{array}$ & $\begin{array}{c}20.76 \pm \\
1.16\end{array}$ & $\begin{array}{c}27.85 \pm \\
1.28\end{array}$ & $\begin{array}{c}3.25 \pm \\
1.08\end{array}$ & $\begin{array}{c}15.60 \pm \\
1.25\end{array}$ & $\begin{array}{c}35.13 \pm \\
0.64\end{array}$ & $\begin{array}{c}2.33 \pm \\
0.33\end{array}$ \\
\hline & 144 & $\begin{array}{c}40.17 \pm \\
2.85\end{array}$ & $\begin{array}{c}57.38 \\
3.12\end{array}$ & $\begin{array}{c}20.76 \pm \\
1.16\end{array}$ & $\begin{array}{c}29.87 \pm \\
1.31\end{array}$ & $\begin{array}{c}3.25 \pm \\
1.08\end{array}$ & $\begin{array}{c}15.60 \pm \\
1.25\end{array}$ & $\begin{array}{c}37.89 \pm \\
0.77\end{array}$ & $\begin{array}{c}1.58 \pm \\
0.27\end{array}$ \\
\hline & 168 & $\begin{array}{c}38.15 \pm \\
2.82\end{array}$ & $\begin{array}{c}63.46 \pm \\
3.22\end{array}$ & $\begin{array}{c}19.75 \pm \\
1.14\end{array}$ & $\begin{array}{c}32.91 \pm \\
1.36\end{array}$ & $\begin{array}{c}3.25 \pm \\
1.08\end{array}$ & $\begin{array}{c}14.59 \pm \\
1.23\end{array}$ & $\begin{array}{c}41.2 \pm \\
0.86\end{array}$ & $\begin{array}{c}0.32 \pm \\
0.33\end{array}$ \\
\hline
\end{tabular}


Effect of variable concentrations of different metals on K.pneumonia and A.lwoffii growth counts

Growth activities of Klebsiella pneumoniae and Acinetobacter lwoffii were affected by metals in single or mixture form present in wastewater. Therefore, it is necessary to study the effect of metals on bacterial growth and hence on metal removal.

Data in Table 7 showed that the growth of Acinetobacter lwoffii was more affected by metal than Klebsiella pneumonia. The growth of Klebsiella pneumonia was highest at 5,10,15 ppm of Fe, 5,10 ppm of $\mathrm{Cr}$ and $5 \mathrm{ppm}$ of $\mathrm{Zn}$, respectively compared with control. While the growth of Acinetobacter lwoffii not affected by $\mathrm{Cr}, \mathrm{Pb}, \mathrm{Fe}$ and $\mathrm{Zn}$ metal at concentration $5 \mathrm{ppm}$. The growth of Klebsiella pneumonia in presence of metal in mixture form has partially affected by increasing mixture concentration. While growth of Acinetobacter lwoffii was more affected at high concentration of metal mixture. Data in Figure 2 \&3 revealed that the ability of Klebsiella pneumoniae and Acinetobacter lwoffii to removal

Table (7) : Effect of different concentrations of single and mixtures metals on bacterial growth count.

\begin{tabular}{|c|c|c|c|}
\hline Sample & $\begin{array}{l}\text { Heavy metal } \\
\text { concentration }\end{array}$ & K.pneumonia & A.lwoffii \\
\hline Control & Without metals & $(280 \pm 7) * 10^{8}$ & $(216 \pm 9) * 10^{6}$ \\
\hline \multirow{3}{*}{$\mathrm{Cr}$ at different concentration } & 5 ppm & $(278 \pm 13) * 10^{8}$ & $(188 \pm 4) * 10^{6}$ \\
\hline & 10 ppm & $(270 \pm 15)^{*} 10^{8}$ & $(280 \pm 9) * 10^{4}$ \\
\hline & 15 ppm & $(225 \pm 15)^{*} 10^{8}$ & $(83 \pm 17)^{*} 10^{3}$ \\
\hline \multirow{3}{*}{$\mathrm{Pb}$ at different concentration } & 5 ppm & $(113 \pm 8)^{*} 10^{8}$ & $(300 \pm 11)^{*} 10^{5}$ \\
\hline & $10 \mathrm{ppm}$ & $(230 \pm 7)^{*} 10^{7}$ & $(283 \pm 8) * 10^{4}$ \\
\hline & 15 ppm & $(121 \pm 10)^{*} 10^{7}$ & $(252 \pm 12)^{*} 10^{3}$ \\
\hline \multirow{3}{*}{ Fe at different concentration } & 5 ppm & $(280 \pm 2) * 10^{8}$ & $(108 \pm 10)^{*} 10^{5}$ \\
\hline & $10 \mathrm{ppm}$ & $(280 \pm 3) * 10^{8}$ & $(63 \pm 11)^{*} 10^{5}$ \\
\hline & 15 ppm & $(280 \pm 3)^{*} 10^{8}$ & $(48 \pm 3)^{*} 10^{5}$ \\
\hline \multirow{3}{*}{$\mathrm{Zn}$ at different concentration } & $5 \mathrm{ppm}$ & $(241 \pm 14)^{*} 10^{8}$ & $(188 \pm 3)^{*} 10^{4}$ \\
\hline & 10 ppm & $(273 \pm 14)^{*} 10^{7}$ & $(103 \pm 18)^{*} 10^{4}$ \\
\hline & 15 ppm & $(221 \pm 7)^{*} 10^{7}$ & $(70 \pm 3) * 10^{4}$ \\
\hline \multirow{3}{*}{$\mathrm{Cu}$ at different concentration } & $5 \mathrm{ppm}$ & $(185 \pm 6)^{*} 10^{8}$ & $(64 \pm 17) * 10^{5}$ \\
\hline & $10 \mathrm{ppm}$ & $(220 \pm 11)^{*} 10^{7}$ & $(81 \pm 7) * 10^{4}$ \\
\hline & $15 \mathrm{ppm}$ & $(135 \pm 8)^{*} 10^{7}$ & $(93 \pm 6) * 10^{3}$ \\
\hline \multirow{3}{*}{$\begin{array}{c}\text { different concentration } \\
\text { of mixtures metals } \\
(\mathrm{Cr}+\mathrm{Pb}+\mathrm{Fe}+\mathrm{Zn}+\mathrm{Cu})\end{array}$} & $5 \mathrm{ppm}$ & $(180 \pm 1)^{*} 10^{8}$ & $(230 \pm 15)^{*} 10^{5}$ \\
\hline & $10 \mathrm{ppm}$ & $(180 \pm 7)^{*} 10^{8}$ & $(118 \pm 7)^{*} 10^{3}$ \\
\hline & 15 ppm & $(173 \pm 14)^{*} 10^{8}$ & $(108 \pm 12)^{*} 10^{3}$ \\
\hline
\end{tabular}


of metal mixture and enhanced the treatment process in wastewater at different concentrations. Our results showed that the maximum mixture removal with highest treatment process were at concentration $5 \mathrm{ppm}$ by two most potent isolates while less remove for metal mixture and treatment process were achieved at high concentration.

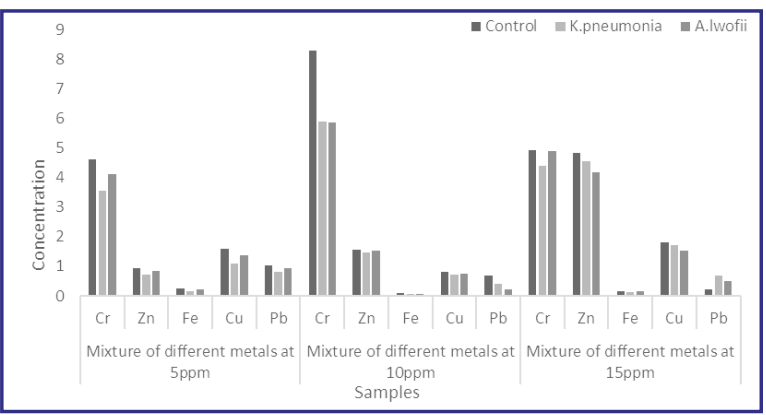

Fig. (2): Metals bioremediation in mixtures of metals $(\mathrm{Cr}$, $\mathrm{Zn}, \mathrm{Fe}, \mathrm{Cu} \& \mathrm{~Pb})$.

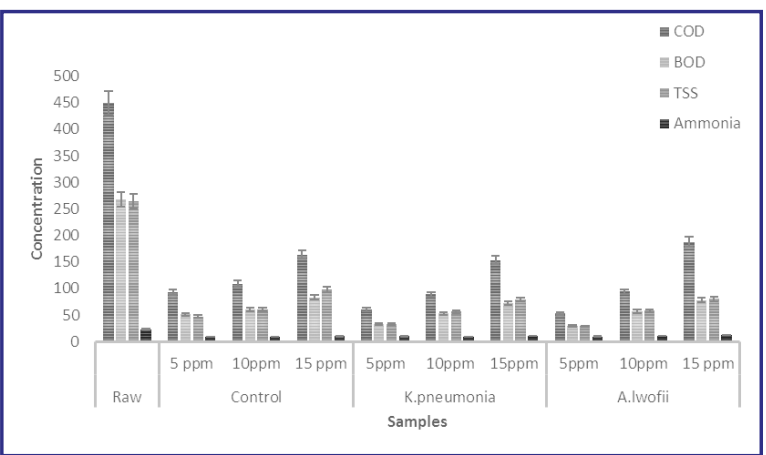

Fig. (3): Waste reduction in wastewater contained different concentrations of metals mixtures.

\section{DISCUSSION}

Environmental condition play an important role in wastewater treatment and heavy metal removal by microorganisms. A number of studies have indicated that the microbial wastewater treatment influenced by treatment conditions (Ravi et al., 2013; Rajesh et al., 2013, Hassan et al., 2015). In this regard, this study focusing on effect of $\mathrm{pH}$, temperature, inoculum size, incubation condition (static and shaker) at different incubation time and heavy metals concentrations affecting on wastewater treatment process. Ravi et al., (2013) reported that optimized factors of treatment process lead to highly efficiency of microbial cell in treatment.

BOD is the amount of oxygen consumed by microorganisms during degrading organic matter in aqueous systems, therefore, decreasing in BOD values during treatment process its positive result for treatment. This decreasing in BOD of the samples may be as a result of the metabolic activities of microorganisms either those indigenous to the wastewater samples or those exogenously added. Kessington et al., (2014) showed that BOD value of samples was varied with remediation time after adding microbial cell, also reported slightly decreasing in BOD for control related to the activity of the indigenous microorganisms. Amenaghawon et al., (2013) investigated the treatment of domestic wastewater supplemented with inorganic fertilizers. They reported reductions in BOD for wastewater and attributed this observation to the activity of the stimulated indigenous microorganisms. The most significant reductions in BOD were obtained for the samples with initial $\mathrm{pH}$ value of 6 followed by that with an initial $\mathrm{pH}$ value of 5 both of which are slightly acidic. On the other hand, very slight BOD reduction was observed for samples with initial $\mathrm{pH} 8$ and 10, both of which are alkaline. The same trend was observed for the samples with initial $\mathrm{pH} 3$ which is an acidic condition. These results show that biodegradation was highly inhibited in the very alkaline and acidic conditions. In our study Klebsiella pneumonia and Acinetobacter lwoffii could be waste reduce at $\mathrm{pH}$ range 5 to 9 but the optimum removal at $\mathrm{pH} 7$, where the values of COD, BOD and TSS for wastewater treated by Klebsiella pneumonia and Acinetobacter lwoffi $i$ were $46.63 \pm 0.69$ and $43.53 \pm 0.65,21.97 \pm 0.33$ and $20.97 \pm 0.31,9.98 \pm 0.15$ and $8.99 \pm 0.13$ respectively when compared with control.

Ravi et al., (2013) mentioned the removal efficiency of pollutant in terms of BOD in the domestic wastewater at various concentration of inoculum were tabulated, they have noticed that, the biore- 
mediation capabilities of consortium inoculation in terms of BOD reduction was $56.12 \%, 61.55 \%$, $63.80 \%, 64.44 \%, 65.13$, and $66.16 \%$ at consortium inoculum size $0.05 \%, .1 \%, 0.2 \%, 0.3 \%, 0.4 \%$ and $0.5 \%$, respectively. As the quantity of wastewater is more, it is found that using more than $0.5 \%$ inoculum is not feasible. Hence, $0.2 \%$ of inoculum is considered as optimized concentration. It is opined that instead of using high concentration of inoculum we have to screen, isolate and enumerate high efficiency strains of microorganisms. Nadirah et al. (2008) reported that $61 \%$ removal of BOD, $97 \%$ COD, $86 \%$ removal of ammonia, $71 \%$ removal of total suspended solids, $50 \%$ removal of nitrate and 53\% removal of oil and grease using Pseudomonas putida, Pseudomonas fluorescence, Xanthobacter sps., and Rhodoccus sps., for treatment of domestic wastewater. Which agreed with our results which reported that the different inoculum size influences on waste removal where the optimum inoculum volume was $0.5 \%$ for Klebsiella pneumonia and the values of COD, BOD and TSS for wastewater treated were $39.44 \pm 0.58,21.97 \pm 0.33$ and $9.98 \pm 0.15$, respectively, while the optimum inoculum size was $2 \%$ for Acinetobacter lwoffii and the values of COD, BOD and TSS for wastewater treated were $43.14 \pm 0.60$, $23.96 \pm 0.36$ and $8.99 \pm 0.13$, respectively, when compared with control. Balaji et al. (2005) reported that $71 \%$ of BOD removal using cow dung as the source of microorganisms with dosing of $3 \%$ for 18 hours Hydraulic Retention Time (HRT) during the experiments conducted for treatment of tannery industry wastewater. Imran, (2007) reported the mean removal efficiency of COD was $87 \%$ after 24 hours of treatment using activated sludge. Chuang et al., (1997) reported that high HRT may help in the production of heterotrophic biomass and finally results in readily biodegradable COD from the sewage. In our study the dynamic aeration with different incubation time affected on the treatment process and the optimum dynamic aeration time was 48 hours for both isolates, where the biodegradation activity in optimum dynamic aeration time lead to the reduction in the values of COD, BOD, TSS and ammonia to $61.10 \pm 3.73,34.77 \pm 1.66,36.12 \pm 2.79$ and 11.27 \pm 0.31 by Klebsiella pneumonia, respectively, while by Acinetobacter lwoffii the values of COD, BOD, TSS and ammonia were 76.62 $\pm 3.44,44.04 \pm 1.56$, $28.76 \pm 1.45$ and $11.14 \pm 0.36$, respectively.

Microbial communities play an importance role in metal removal in wastewater due to it is less cost, with non-hazardous end products (Oghenerobor $\boldsymbol{e} t$ al., 2014). During pollutant removal, the microbe(s) alter the metal chemistry and mobility through either reduction, accumulation, mobilization or immobilization (Faryal and Hameed, 2005). The microbial remediation of toxic metals is said to occur in two ways: direct and indirect reduction (Sinha $\boldsymbol{e t}$ al., 2009). In this investigation the optimum metals removal with best treatment process was at $5 \mathrm{ppm}$ for both isolates where the values of treated $\mathrm{Cr}, \mathrm{Zn}$, $\mathrm{Fe}, \mathrm{Cu}$ and $\mathrm{Pb}$ by Klebsiella pneumonia and Acinetobacter lwoffii were $3.566 \pm 0.025$ and $4.108 \pm$ $0.074,0.706 \pm 0.002$ and $0.856 \pm 0.013,0.172 \pm$ 0.002 and $0.209 \pm 0.003,1.102 \pm 0.002$ and $1.383 \pm$ $0.026,0.801 \pm 0.003$ and $0.939 \pm 0.003$ respectively, while the values of COD, BOD, TSS and ammonia of treated wastewater by Klebsiella pneumonia were $60.7 \pm 3.51,32.3 \pm 2.52,33.7 \pm 0.58$ and $10.3 \pm 0.17$ and by Acinetobacter lwoffi $i$ were $53 \pm 3,29.3 \pm$ $0.58,28.7 \pm 0.58$ and $9.4 \pm 0.14$ respectively.

\section{REFERENCES}

- Amenaghawon, N.A.; Asegame, P.A. and Obahiagbon, K.O. (2013): "Potential Application of Urea and NPK 15:15:15 Fertilizers as Biostimulants in the Bioremediation of Domestic Wastewater". American Journal of Environmental Protection. 1(4): 91.

- Balaji, V.; Datta, S. and Bhattacharjee, C. (2005): Evaluation on biological treatment for industrial wastewater.IE (I) Journal.CH. 85: 39.

- Bécares E. (2006): Limnology of natural systems for 
wastewater treatment, Ten years of experiences at the experimental field for low-cost sanitation in Mansilla de lasMulas, León, Spain. Limnética, 25, 143.

- Brix, H. (1994): Constructed wetlands for municipal wastewater treatment in Europe, In: Mitsch, W.J. editor. Global Wetlands: Old World and New, Amsterdam, the Netherlands, Elsevier, 325.

- Chuang, S.H.; Ouyang, C.F. and Yuang, H.C. (1997): Effect of SRT and DO on nutrient removal in a combined as-biolfilm process. Wat.Sci.Tech. 36(12): 2019.

- Davies, P. S. (2005): The Biological Basis of Wastewater Treatment. West of Scotland Science Park, Strathkelvin Instruments: 1-3.

- Easa, A. and Abou-Rayan, A. (2010): Domestic wastewater effect on the pollution of the groundwater in rural areas in Egypt. Fourteenth International Water Technology Conference, Cairo, Egypt.

- El Shahawy, M.R. (2007): Enhanced aerobic degradation of some toxic hydrocarbon pollutant. Ph.D., in sciences of Microbiology. Faculty of Science, Ain Shams University, Egypt.

- ESCWA (2010): Waste-Water Treatment Technologies-A General Review, Economic and Eocial Commission for Western Asia, United Nations, New York (ESCWA). http://www. escwa. un. org/information/ publications/edit/upload/sdpd-03-6. pdf accessed.

- $\quad$ Eugene, W. R.; Rodger, B. B.; Andrew D. E. and Lenore S. C. (2012): Standard Methods for the examination of Water and Wastewater, 22nd Edition, American Public Health Association, American Water Works Association, Water Environment Federation, USA.

- $\quad$ Faryal, R. and Hameed, A. (2005): Isolation and characterization of various fungal strains from textile effluent for their use in bioremediation. Pakistani Journal of Botany, 37(4): 1003.
- $\quad$ FEW and APHA, (2012): Standard Methods for the Examination of Water and Wastewater, 22nd Ed., Federation Water Environment (FEW) and American Public Health Association(APHA), Washington, DC, USA.

- Fouda, A., Hassan, S., Azab, M. S and Saied, E. (2016): Decolorization of different azo dyes and detoxification of dyeing wastewater by Pseudomonas stutzeri (SB_13) isolated from textile dyes effluent. British Biotechnology Journal. 15(4): 1.

- Hassan, S., Fouda, A., Azab, M. S and Saied, E. (2015): Biological decolorization of different azo dyes using two bacterial strains of Klebsiella spp. and their consortium. Inter. J. Environ. Biolo. 5(4): 104.

- Imran, H. (2007): Performance evaluation of biosimulator for treating domestic wastewater using activated sludge treatment system J. Appl. Sci. Environ. Manage. 11 (2): 129.

- Kessington, O.O; Andrew, N.A. and Elvis O.A. (2014): Effect of initial $\mathrm{pH}$ on the bioremediation of crude oil polluted water using a consortium of microbes. The Pacific Journal of Science and Technology.15 (1): 452.

- Lin, S. D. (2007): Water and Wastewater Calculations Manual. C. C. Lee. United States, McGraw-Hill Companies: 531.

- Mara, D.D., Mills,S.W., Pearson, H.W. and Alabaster, G.P. (1992): Waste stabilization ponds, A viable alternative for small community treatment systems. JIWEM 6, 8 .

- Mohamed, A.G.; El Safty, A.M. and Siha, M.S. (2013): Current situation of water pollution and its effect on aquatic life in Egypt. Egyptian Journal of Occupational Medicine. 37 (1) : 95.

- $\quad$ Nadirah, I.; Zaharah, I.; Zaiton, A.M.; Siti Haryani, C.K. and Fadhil, M. (2008): Application of Bioparticle in Biofilter for Wastewater Treatment. In- 
ternational Conference and Expo on Environmental Management and Technologies, (ICEEMAT), 10-12 2008. Proceeding Booklet.

- Oghenerobor, B.A; Gladys, O.O. and Tomilola, D.O.(2014): Heavy metal pollutants in wastewater effluents: Sources,effects and remediation. Advances in Bioscience and Bioengineering.2(4): 37.

- Puigagut, J.; Villaseñor, J.; Salas, J.J.; Bécares, E. and García, J. (2007): Subsurface-flow constructed wetlands in Spain for the sanitation of small communities: a comparative study. Ecol Eng. (30):9.

- Rajesh, S.; Narsi, R.; Bishnoi; Anita, K. and Rajender, K. (2013): Synergism of Pseudomonas aeruginosa and $\mathrm{Fe}^{0}$ for treatment of heavy metal contaminated effluents using small scale laboratory reactor. Bioresource Technology.127: 49.
- Ravi, B.k.; Lakshmi, P.M.; Srinivasarao, D. and Sambasiva, R.A.O. (2013): Bioremediation of sewage using specific consortium of Microorganisms International Journal of Research in Applied. 1 (6): 15.

- Sinha, R.K.; Valani, D.; Sinha, S.; Singh, S. and Herat, S. (2009): Bioremediation of contaminated sites: A low-cost nature's biotechnology for environmental cleanup by versatile microbes, plants and earthworms. In Faerber, T. and Herzog, J. (Eds), Solid Waste Management and Environmental Remediation.

- Vymazal, J. (2002): The use of sub-surface constructed wetlands for wastewater treatment in the Czech Republic, 10 years' experience. Ecological Engineering. 18(5), 633. 